\title{
Active power loss reduction by opposition based kidney search algorithm
}

\author{
K. Lenin \\ Department of EEE, Prasad V. Potluri Siddhartha Institute of Technology, India
}

\begin{tabular}{l}
\hline \hline Article Info \\
\hline Article history: \\
Received Apr 30, 2019 \\
Revised Jul 11, 2019 \\
Accepted Jul 27, 2019 \\
\hline
\end{tabular}

Keywords:

Opposition based kidney search algorithm Optimal reactive power Transmission loss

\begin{abstract}
In this work Opposition based Kidney Search Algorithm (OKS) is used to solve the optimal reactive power problem. Kidney search algorithm imitates the various sequences of functions done by biological kidney. Opposition based learning (OBL) stratagem is engaged to commence the algorithm. This is to make certain high-quality of preliminary population and to expand the exploration steps in case of stagnation of the most excellent solutions. Opposition based learning (OBL) is one of the influential optimization tools to boost the convergence speed of different optimization techniques. The thriving implementation of the OBL engages evaluation of opposite population and existing population in the similar generation to discover the superior candidate solution of a given reactive power problem. Proposed Opposition based Kidney Search Algorithm (OKS) has been tested in standard IEEE 14, 30, 57,118,300 bus test systems and simulation results show that the proposed algorithm reduced the real power loss efficiently.
\end{abstract}

Copyright $@ 2019$ Institute of Advanced Engineering and Science. All rights reserved.

\section{Corresponding Author:}

K. Lenin, Department of EEE, Prasad V. Potluri Siddhartha Institute of Technology,

Kanuru, Vijayawada, Andhra Pradesh - 520007.

Email: gklenin@gmail.com

\section{INTRODUCTION}

Reactive power problem plays a key role in secure and economic operations of power system. Optimal reactive power problem has been solved by variety of types of methods [1-6]. Nevertheless, numerous scientific difficulties are found while solving problem due to an assortment of constraints. Evolutionary techniques [7-15] are applied to solve the reactive power problem, but the main problem is many algorithms get stuck in local optimal solution \& failed to balance the Exploration \& Exploitation during the search of global solution. In this work Opposition based Kidney Search Algorithm (OKS) is used to solve the optimal reactive power problem. Kidney search algorithm imitates the various sequences of functions done by biological kidney. In preliminary segment, a capricious population of feasible solutions is formed and re-absorption, secretion, excretion are replicated in the exploration procedure to verify different conditions well-established to the algorithm. Opposition based learning (OBL) stratagem is engaged to commence the algorithm. This is to make certain high-quality of preliminary population and to expand the exploration steps in case of stagnation of the most excellent solutions. Opposition based learning (OBL) is one of the influential optimization tools to boost the convergence speed of different optimization techniques. The thriving implementation of the OBL engages evaluation of opposite population and existing population in the similar generation to discover the superior candidate solution of a given reactive power problem. In all oppositional based optimization; the conception of OBL is used in the initialization procedure and as well as in each iteration using the generation jumping rate, Jr. Proposed Opposition based Kidney Search Algorithm (OKS) has been tested in standard IEEE 14, 30, 57,118,300 bus test systems and simulation results show the projected algorithm reduced the real power loss comprehensively. 


\section{PROBLEM FORMULATION}

Objective of the problem is to reduce the true power loss

$\mathrm{F}=\mathrm{P}_{\mathrm{L}}=\sum_{\mathrm{k} \in \mathrm{Nbr}} \mathrm{g}_{\mathrm{k}}\left(\mathrm{V}_{\mathrm{i}}^{2}+\mathrm{V}_{\mathrm{j}}^{2}-2 \mathrm{~V}_{\mathrm{i}} \mathrm{V}_{\mathrm{j}} \cos \theta_{\mathrm{ij}}\right)$

Voltage deviation given as follows

$\mathrm{F}=\mathrm{P}_{\mathrm{L}}+\omega_{\mathrm{v}} \times$ Voltage Deviation

Voltage deviation given by

Voltage Deviation $=\sum_{\mathrm{i}=1}^{\mathrm{Npq}}\left|\mathrm{V}_{\mathrm{i}}-1\right|$

Constraint (Equality)

$P_{G}=P_{D}+P_{L}$

Constraints (Inequality)

$$
\begin{aligned}
& \mathrm{P}_{\text {gslack }}^{\min } \leq \mathrm{P}_{\text {gslack }} \leq \mathrm{P}_{\text {gslack }}^{\text {max }} \\
& \mathrm{Q}_{\mathrm{gi}}^{\text {min }} \leq \mathrm{Q}_{\mathrm{gi}} \leq \mathrm{Q}_{\mathrm{gi}}^{\max }, \mathrm{i} \in \mathrm{N}_{\mathrm{g}} \\
& \mathrm{V}_{\mathrm{i}}^{\text {min }} \leq \mathrm{V}_{\mathrm{i}} \leq \mathrm{V}_{\mathrm{i}}^{\text {max }}, \mathrm{i} \in \mathrm{N} \\
& \mathrm{T}_{\mathrm{i}}^{\min } \leq \mathrm{T}_{\mathrm{i}} \leq \mathrm{T}_{\mathrm{i}}^{\max }, \mathrm{i} \in \mathrm{N}_{\mathrm{T}} \\
& \mathrm{Q}_{\mathrm{c}}^{\text {min }} \leq \mathrm{Q}_{\mathrm{c}} \leq \mathrm{Q}_{\mathrm{C}}^{\max }, \mathrm{i} \in \mathrm{N}_{\mathrm{C}}
\end{aligned}
$$

\section{OPPOSITION BASED KIDNEY SEARCH ALGORITHM}

Kidney search algorithm imitates the various sequences of functions done by biological kidney. Filtration, Re-absorption, Secretion, Excretion plays key function in the function of the kidney. In preliminary segment, a capricious population of feasible solutions is formed and re-absorption, secretion, excretion are replicated in the exploration procedure to verify different conditions well-established to the algorithm. Algorithm is built to perk up the exploration even a potential solution stirred to waste (W) and it will be fetch back to the filtered blood (FB). Glomerular filtration rate (GFR) test is employed to authenticate the robustness of kidney. The test roughly gives the capability of blood that pass all the way through the glomeruli every minute. Depending on the GFR test outcome which is less than 15 or falls between 15 and 60 or is more than 60 a meticulous action will be accomplished. This process executed to perk up the rate of exploration and to discover the optimal solution. The GFR testing process is added at the ending of iterations. When GFR level is less than 15, the method is recurring with the population in Filtered Blood. When GFR level is between 15 and 60, development of realistic solutions in Filtered blood is applied as a treatment for abridged kidney function. This sequence augments the searching capability and is designed to assist the algorithm in detection of improved solution. If the GFR level is larger than 60, then kidney function is ordinary, in which case no extra development is added to algorithm.

Movement equation as follows

$$
Z_{i+1}=Z_{i}+\operatorname{rand}\left(Z_{\text {best }}-Z_{i}\right)
$$

Filtering of the solutions is done with a filtration rate and Calculation of the filtration rate $\left(l_{r}\right)$ is done using the following equation

$$
l_{r}=\beta \times \frac{\sum_{i=1}^{s} f\left(y_{i}\right)}{s}
$$

$\beta$ is a constant value between 0 and 1 and is attuned in advance. s represents the size of the population. $f\left(y_{i}\right)$ represents an objective function of solution $\mathrm{y}$ at ith iteration [16]. In every iteration,

Int. J. of Adv. in Appl. Sci. Vol. 8, No. 3, September 2019: 217 - 224 
previous to integration the Filtration of blood (FB) and waste (W) will be population for the subsequent iteration, the algorithm compute the GFR level based on the fr in FB

Glomerular filtration rate minimum $=120-\left(\frac{f r_{F B} * 100}{f r}\right)$

Define the Population

Calculate approximate solution in the population

Most excellent solution $Z_{\text {best }}$, is found

By (11) find the Filtration rate- $l_{r}$,

Define waste (W)

Define filtered blood (FB)

Number of iteration will be found

Do while (iteration $<$ number of iterations)

For $Z_{i}$; compute new $Z_{i}$ by using (10)

Check the value of $Z_{i}$ using $l_{r}$

If $Z_{i}$ allocated to $\mathrm{W}$ then place on re-absorption and produce $Z_{\text {new }}$ by using (10)

If re-absorption is not fulfilled then $Z_{\text {new }}$ will not be part of FB

Eradicate $Z_{i}$ from $\mathrm{W}$ (excretion)

Place randomly $\mathrm{Z}$ into $\mathrm{W}$ to exchange $Z_{i}$

End if

$Z_{i}$ is reabsorbed

Else

If it is superior than the $Z_{\text {worst }}$ in $F B$

$Z_{\text {worst }}$ is secreted

Calculate the GFR level solutions in FB by using (12)

if $15<$ GFR level $<60$; then implement movement of solutions in FB

End if

if GFR level $<15$; then algorithm proceeded with the same population in $F B$

End if

End if

End for

Rank the $Z_{s}$ from FB and modernize the $Z_{\text {best }}$

Merge $\mathrm{W}$ and FB

By (11) amend filtration rate $l_{r}$

End while

Return $Z_{\text {best }}$

In this work Opposition based Kidney Search Algorithm (OKS) is used to solve the problem. Opposition based learning (OBL) stratagem is engaged to commence the algorithm. This is to make certain high-quality of preliminary population and to expand the exploration steps in case of stagnation of the most excellent solutions. Opposition based learning (OBL) is one of the influential optimization tools to boost the convergence speed of different optimization techniques [17]. The thriving implementation of the OBL engages evaluation of opposite population and existing population in the similar generation to discover the superior candidate solution of a given reactive power problem. The conception of opposite number requirements is to be defined to explain OBL.

Let $N(N \in[x, y])$ be a real number and the $N^{o}$ (opposite number) can be defined as follows

$N^{o}=x+y-N$

In the exploration space it has been extended as

$N_{i}^{o}=x_{i}+y_{i}-N_{i}$

Where $\left(N_{1}, N_{2}, \ldots N_{d}\right)$ is a point in the dimensional search space, $N_{i} \in\left[x_{i}, y_{i}\right], i \rightarrow\{1,2,3, \ldots d\}$

In all oppositional based optimization; the conception of OBL is used in the initialization procedure and as well as in each iteration using the generation jumping rate, Jr.

Active power loss reduction by opposition based kidney search algorithm (K. Lenin) 
a. Begin

b. Engender OBL based population

c. Calculate each " $Z$ " in the population and fix the " $Z_{\text {best" }}$ "

d. Produce new-fangled " $Z$ " for " $Z_{i}$ " based on mutual information based switching

e. Apply the filtration operator

f. Is " $Z_{i}$ " assigned as "W"? ; if "Yes" apply the reabsorption operator; or check is " $Z_{i}$ " better than the " $Z_{\text {worst }}$ " - if yes then secrete " $Z_{\text {worst }}$ " from FB or secrete " $Z_{i}$ "

g. Can " $Z_{\text {new }}$ " be assigned as FB? If yes remove " $Z_{i}$ " from $W$ and insert a random " $Z$ " into "W"

h. Have all " $Z$ " " have been met?

i. If "yes" engender $\bar{Z}_{\text {best }}$ or else go to step "d"

j. Is " $\bar{Z}_{\text {best }}$ " better than the " $Z_{\text {worst }}$ " in FB? if "yes" replace " $Z_{\text {worst }}$ " with " $\bar{Z}_{\text {best }}$ "

k. Or else update " $Z_{\text {best }}$ ", merge $\mathrm{W}, \mathrm{FB}$ modernize the filtration rate

1. Is end criterion reached? if yes stop or else go to step " $\mathrm{d}$ "

\section{SIMULATION STUDY}

At first in standard IEEE 14 bus system the validity of the proposed Opposition based Kidney Search Algorithm (OKS) has been tested, Table 1 shows the constraints of control variables Table 2 shows the limits of reactive power generators and comparison results are presented in Table 3.

Table 1. Constraints of control variables

\begin{tabular}{cccc}
\hline \multirow{2}{*}{ System } & Variables & $\begin{array}{c}\text { Minimum } \\
(\mathrm{PU})\end{array}$ & $\begin{array}{c}\text { Maximum } \\
(\mathrm{PU})\end{array}$ \\
\hline \multirow{3}{*}{ IEEE 14 Bus } & Generator Voltage & 0.95 & 1.1 \\
& Transformer Tap & 0.9 & 1.1 \\
& VAR Source & 0 & 0.20 \\
\hline
\end{tabular}

Table 2. Constrains of reactive power generators

\begin{tabular}{cccc}
\hline System & Variables & $\begin{array}{c}\text { Q Minimum } \\
(\mathrm{PU})\end{array}$ & $\begin{array}{c}\text { Q Maximum } \\
(\mathrm{PU})\end{array}$ \\
\hline \multirow{3}{*}{ IEEE 14 Bus } & 1 & 0 & 10 \\
& 2 & -40 & 50 \\
& 3 & 0 & 40 \\
& 6 & -6 & 24 \\
& 8 & -6 & 24 \\
\hline
\end{tabular}

Table 3. Simulation results of IEEE -14 system

\begin{tabular}{ccccccc}
\hline Control variables & Base case & MPSO [18] & PSO [18] & EP [18] & SARGA [18] & OKS \\
\hline$V G-1$ & 1.060 & 1.100 & 1.100 & NR* & NR* & 1.012 \\
$V G-2$ & 1.045 & 1.085 & 1.086 & 1.029 & 1.060 & 1.028 \\
$V G-3$ & 1.010 & 1.055 & 1.056 & 1.016 & 1.036 & 1.024 \\
$V G-6$ & 1.070 & 1.069 & 1.067 & 1.097 & 1.099 & 1.016 \\
$V G-8$ & 1.090 & 1.074 & 1.060 & 1.053 & 1.078 & 1.019 \\
Tap 8 & 0.978 & 1.018 & 1.019 & 1.04 & 0.95 & 0.910 \\
Tap 9 & 0.969 & 0.975 & 0.988 & 0.94 & 0.95 & 0.902 \\
Tap 10 & 0.932 & 1.024 & 1.008 & 1.03 & 0.96 & 0.915 \\
$Q C-9$ & 0.19 & 14.64 & 0.185 & 0.18 & 0.06 & 0.146 \\
$P G$ & 272.39 & 271.32 & 271.32 & NR* & NR* & 271.09 \\
$Q G$ (Mvar) & 82.44 & 75.79 & 76.79 & NR* & NR* & 75.17 \\
Reduction in PLoss (\%) & 0 & 9.2 & 9.1 & 1.5 & 2.5 & 18.75 \\
Total PLoss (Mw) & 13.550 & 12.293 & 12.315 & 13.346 & 13.216 & 11.009 \\
\hline NR*
\end{tabular}

NR* - Not reported.

Then the proposed Opposition based Kidney Search Algorithm (OKS) has been tested, in IEEE 30 Bus system. Table 4 shows the constraints of control variables, Table 5 shows the limits of reactive power generators and comparison results are presented in Table 6.

Table 4. Constraints of control variables

\begin{tabular}{cccc}
\hline \multirow{2}{*}{ System } & Variables & $\begin{array}{c}\text { Minimum } \\
(\mathrm{PU})\end{array}$ & $\begin{array}{c}\text { Maximum } \\
(\mathrm{PU})\end{array}$ \\
\hline \multirow{2}{*}{ IEEE 30} & Generator Voltage & 0.95 & 1.1 \\
Bus & Transformer Tap & 0.9 & 1.1 \\
& VAR Source & 0 & 0.20 \\
\hline
\end{tabular}

Table 5. Constrains of reactive power generators

\begin{tabular}{cccc}
\hline System & Variables & $\begin{array}{c}\text { Q Minimum } \\
(\mathrm{PU})\end{array}$ & $\begin{array}{c}\text { Q Maximum } \\
(\mathrm{PU})\end{array}$ \\
\hline \multirow{2}{*}{ IEEE 30 } & 1 & 0 & 10 \\
Bus & 2 & -40 & 50 \\
& 5 & -40 & 40 \\
& 8 & -10 & 40 \\
& 11 & -6 & 24 \\
& 13 & -6 & 24 \\
\hline
\end{tabular}


Int. J. of Adv. in Appl. Sci.

ISSN: $2252-8814$

Table 6. Simulation results of IEEE -30 system

\begin{tabular}{|c|c|c|c|c|c|c|}
\hline Control variables & Base case & MPSO [18] & PSO [18] & EP [18] & SARGA [18] & OKS \\
\hline$V G-1$ & 1.060 & 1.101 & 1.100 & $\mathrm{NR}^{*}$ & $\mathrm{NR}^{*}$ & 1.028 \\
\hline$V G-2$ & 1.045 & 1.086 & 1.072 & 1.097 & 1.094 & 1.029 \\
\hline$V G-5$ & 1.010 & 1.047 & 1.038 & 1.049 & 1.053 & 1.017 \\
\hline$V G-8$ & 1.010 & 1.057 & 1.048 & 1.033 & 1.059 & 1.028 \\
\hline$V G-12$ & 1.082 & 1.048 & 1.058 & 1.092 & 1.099 & 1.019 \\
\hline VG-13 & 1.071 & 1.068 & 1.080 & 1.091 & 1.099 & 1.026 \\
\hline Tap11 & 0.978 & 0.983 & 0.987 & 1.01 & 0.99 & 0.920 \\
\hline Tap12 & 0.969 & 1.023 & 1.015 & 1.03 & 1.03 & 0.921 \\
\hline Tap15 & 0.932 & 1.020 & 1.020 & 1.07 & 0.98 & 0.922 \\
\hline Tap36 & 0.968 & 0.988 & 1.012 & 0.99 & 0.96 & 0.929 \\
\hline QC10 & 0.19 & 0.077 & 0.077 & 0.19 & 0.19 & 0.094 \\
\hline QC24 & 0.043 & 0.119 & 0.128 & 0.04 & 0.04 & 0.107 \\
\hline$P G(\mathrm{MW})$ & 300.9 & 299.54 & 299.54 & $\mathrm{NR}^{*}$ & $\mathrm{NR}^{*}$ & 297.08 \\
\hline$Q G($ Mvar $)$ & 133.9 & 130.83 & 130.94 & $\mathrm{NR}^{*}$ & $\mathrm{NR}^{*}$ & 131.78 \\
\hline Reduction in PLoss (\%) & 0 & 8.4 & 7.4 & 6.6 & 8.3 & 14.46 \\
\hline Total PLoss (Mw) & 17.55 & 16.07 & 16.25 & 16.38 & 16.09 & 15.012 \\
\hline
\end{tabular}

NR* - Not reported.

Then the proposed Opposition based Kidney Search Algorithm (OKS) has been tested, in IEEE 57 Bus system. Table 7 shows the constraints of control variables, Table 8 shows the limits of reactive power generators and comparison results are presented in Table 9.

Table 7. Constraints of control variables

\begin{tabular}{cccc}
\hline \multirow{2}{*}{ System } & Variables & $\begin{array}{c}\text { Minimum } \\
(\mathrm{PU})\end{array}$ & $\begin{array}{c}\text { Maximum } \\
(\mathrm{PU})\end{array}$ \\
\hline \multirow{3}{*}{ IEEE 57 Bus } & Generator Voltage & 0.95 & 1.1 \\
& Transformer Tap & 0.9 & 1.1 \\
& VAR Source & 0 & 0.20 \\
\hline
\end{tabular}

Table 8. Constrains of reactive power generators

\begin{tabular}{cccc}
\hline System & Variables & $\begin{array}{c}\text { Q Minimum } \\
(\mathrm{PU})\end{array}$ & $\begin{array}{c}\text { Q Maximum } \\
(\mathrm{PU})\end{array}$ \\
\hline \multirow{2}{*}{ IEEE 57 } & 1 & -140 & 200 \\
Bus & 2 & -17 & 50 \\
& 3 & -10 & 60 \\
& 6 & -8 & 25 \\
& 8 & -140 & 200 \\
& 9 & -3 & 9 \\
& 12 & -150 & 155 \\
\hline
\end{tabular}

Table 9. Simulation results of IEEE -57 system

\begin{tabular}{|c|c|c|c|c|c|c|}
\hline Control variables & Base case & MPSO [18] & PSO [18] & CGA [18] & AGA [18] & $\mathrm{OKS}$ \\
\hline$V G 1$ & 1.040 & 1.093 & 1.083 & 0.968 & 1.027 & 1.012 \\
\hline$V G 2$ & 1.010 & 1.086 & 1.071 & 1.049 & 1.011 & 1.018 \\
\hline$V G 3$ & 0.985 & 1.056 & 1.055 & 1.056 & 1.033 & 1.028 \\
\hline$V G 6$ & 0.980 & 1.038 & 1.036 & 0.987 & 1.001 & 1.027 \\
\hline$V G 8$ & 1.005 & 1.066 & 1.059 & 1.022 & 1.051 & 1.029 \\
\hline$V G 9$ & 0.980 & 1.054 & 1.048 & 0.991 & 1.051 & 1.030 \\
\hline$V G 12$ & 1.015 & 1.054 & 1.046 & 1.004 & 1.057 & 1.040 \\
\hline Tap 19 & 0.970 & 0.975 & 0.987 & 0.920 & 1.030 & 0.900 \\
\hline Tap 20 & 0.978 & 0.982 & 0.983 & 0.920 & 1.020 & 0.909 \\
\hline Tap 31 & 1.043 & 0.975 & 0.981 & 0.970 & 1.060 & 0.906 \\
\hline Tap 35 & 1.000 & 1.025 & 1.003 & $\mathrm{NR}^{*}$ & NR* & 1.018 \\
\hline Tap 36 & 1.000 & 1.002 & 0.985 & $\mathrm{NR}^{*}$ & $\mathrm{NR} *$ & 1.014 \\
\hline Tap 37 & 1.043 & 1.007 & 1.009 & 0.900 & 0.990 & 1.008 \\
\hline Tap 41 & 0.967 & 0.994 & 1.007 & 0.910 & 1.100 & 0.940 \\
\hline Tap 46 & 0.975 & 1.013 & 1.018 & 1.100 & 0.980 & 1.010 \\
\hline Tap 54 & 0.955 & 0.988 & 0.986 & 0.940 & 1.010 & 0.920 \\
\hline Tap 58 & 0.955 & 0.979 & 0.992 & 0.950 & 1.080 & 0.930 \\
\hline Tap 59 & 0.900 & 0.983 & 0.990 & 1.030 & 0.940 & 0.921 \\
\hline Tap 65 & 0.930 & 1.015 & 0.997 & 1.090 & 0.950 & 1.005 \\
\hline Tap 66 & 0.895 & 0.975 & 0.984 & 0.900 & 1.050 & 0.931 \\
\hline Tap 71 & 0.958 & 1.020 & 0.990 & 0.900 & 0.950 & 1.008 \\
\hline Tap 73 & 0.958 & 1.001 & 0.988 & 1.000 & 1.010 & 1.010 \\
\hline Tap 76 & 0.980 & 0.979 & 0.980 & 0.960 & 0.940 & 0.942 \\
\hline Tap 80 & 0.940 & 1.002 & 1.017 & 1.000 & 1.000 & 1.004 \\
\hline$Q C 18$ & 0.1 & 0.179 & 0.131 & 0.084 & 0.016 & 0.152 \\
\hline$Q C 25$ & 0.059 & 0.176 & 0.144 & 0.008 & 0.015 & 0.141 \\
\hline$Q C 53$ & 0.063 & 0.141 & 0.162 & 0.053 & 0.038 & 0.120 \\
\hline$P G(\mathrm{MW})$ & 1278.6 & 1274.4 & 1274.8 & 1276 & 1275 & 1272.92 \\
\hline$Q G$ (Mvar) & 321.08 & 272.27 & 276.58 & 309.1 & 304.4 & 272.01 \\
\hline Reduction in PLoss (\%) & 0 & 15.4 & 14.1 & 9.2 & 11.6 & 24.12 \\
\hline Total PLoss (Mw) & 27.8 & 23.51 & 23.86 & 25.24 & 24.56 & 21.092 \\
\hline
\end{tabular}


Then the proposed Opposition based Kidney Search Algorithm (OKS) has been tested, in IEEE 118 Bus system. Table 10 shows the constraints of control variables and the comparison results are presented in Table 11 as shown in appendix.

Table 10. Constraints of control variables

\begin{tabular}{cccc}
\hline System & Variables & Minimum (PU) & Maximum (PU) \\
\hline \multirow{3}{*}{ IEEE 118 Bus } & Generator Voltage & 0.95 & 1.1 \\
& Transformer Tap & 0.9 & 1.1 \\
& VAR Source & 0 & 0.20 \\
\hline
\end{tabular}

Then IEEE 300 bus system [19] is used as test system to validate the performance of the Opposition based Kidney Search Algorithm (OKS). Table 12 shows the comparison of real power loss obtained after optimization.

Table 12. Comparison of real power loss

\begin{tabular}{ccccc}
\hline Parameter & Method EGA [20] & Method EEA [20] & Method CSA [21] & OKS \\
\hline PLOSS (MW) & 646.2998 & 650.6027 & 635.8942 & 613.0974 \\
\hline
\end{tabular}

\section{CONCLUSION}

In this work Opposition based Kidney Search Algorithm (OKS) has been successfully applied for solving optimal reactive power problem. Opposition based learning (OBL) stratagem is engaged to commence the algorithm. The prosperous execution of the OBL employ assessment of opposite population and existing population in the analogous generation to find out the better candidate solution of a given reactive power problem. In all oppositional based optimization; the conception of OBL is used in the initialization procedure and as well as in each iteration using the generation jumping rate. Proposed Opposition based Kidney Search Algorithm (OKS) has been tested in standard IEEE 14, 30, 57,118,300 bus test systems and simulation results show that the proposed algorithm reduced the real power loss efficiently.

\section{REFERENCES}

[1] K. Y. Lee., "Fuel-cost minimisation for both real and reactive-power dispatches," Proceedings Generation, Transmission and Distribution Conference, vol. 131(3), pp. 85-93, 1984.

[2] N. I. Deeb, "An efficient technique for reactive power dispatch using a revised linear programming approach," Electric Power System Research, vol. 15(2), pp. 121-134, 1998.

[3] M. R. Bjelogrlic, M. S. Calovic, and B. S. Babic, "Application of Newton's optimal power flow in voltage/reactive power control," IEEE Trans Power System, vol. 5(4), pp. 1447-1454, 1990.

[4] S. Granville, "Optimal reactive dispatch through interior point methods," IEEE Transactions on Power System, vol. 9(1), pp. 136-146, 1994.

[5] N. Grudinin, "Reactive power optimization using successive quadratic programming method," IEEE Transactions on Power System, vol. 13(4), pp. 1219-1225, 1998.

[6] Ng Shin Mei, R. Sulaiman, M. H. Mustaffa, Z., and Daniyal, H., "Optimal reactive power dispatch solution by loss minimization using moth-flame optimization technique," Appl. Soft Comput., vol. 59, pp. 210-222, 2017.

[7] Chen, G. Liu, L. Zhang, Z, and Huang, S., "Optimal reactive power dispatch by improved GSA-based algorithm with the novel strategies to handle constraints," Appl. Soft Comput. 2017, vol. 50, pp. 58-70, 2017.

[8] Naderi, E, Narimani, H, Fathi, M, and Narimani, M.R., "A novel fuzzy adaptive configuration of particle swarm optimization to solve large-scale optimal reactive power dispatch," Appl. Soft Comput. 2017, vol. 53, pp. 441-456, 2017.

[9] Heidari, A.A, Ali Abbaspour, R, and Rezaee Jordehi, A., "Gaussian bare-bones water cycle algorithm for optimal reactive power dispatch in electrical power systems," Appl. Soft Comput. 2017, vol. 57, pp. 657-671, 2017.

[10] Mahaletchumi Morgan, Nor Rul Hasma Abdullah, Mohd Herwan Sulaiman, Mahfuzah Mustafa, and Rosdiyana Samad., "Benchmark Studies on Optimal Reactive Power Dispatch (ORPD) Based Multi-objective Evolutionary Programming (MOEP) Using Mutation Based on Adaptive Mutation Adapter (AMO) and Polynomial Mutation Operator (PMO)," Journal of Electrical Systems, 12-1, 2016.

[11] Rebecca Ng Shin Mei, Mohd Herwan Sulaiman, and Zuriani Mustaffa., "Ant Lion Optimizer for Optimal Reactive Power Dispatch Solution," Journal of Electrical Systems, Special Issue AMPE2015, pp. 68-74, 2016.

[12] P. Anbarasan and T. Jayabarathi, "Optimal reactive power dispatch problem solved by symbiotic organism search algorithm," Innovations in Power and Advanced Computing Technologies, pp. 1-8, 2017.

[13] Gagliano A. and Nocera F. "Analysis of the performances of electric energy storage in residential applications," International Journal of Heat and Technology, vol. 35(1), pp. S41-S48, 2017.

Int. J. of Adv. in Appl. Sci. Vol. 8, No. 3, September 2019: 217 - 224 
Int. J. of Adv. in Appl. Sci.

[14] Caldera M, Ungaro P, Cammarata G, and Puglisi G., "Survey-based analysis of the electrical energy demand in Italian households," Mathematical Modelling of Engineering Problems, vol. 5(3), pp. 217-224, 2018.

[15] M. Basu., "Quasi-oppositional differential evolution for optimal reactive power dispatch," Electrical Power and Energy Systems, vol. 78, pp. 29-40, 2016.

[16] Jaddi, N. S., J. Alvankarian, and S. Abdullah., "Kidney-inspired algorithm for optimization problems," Communications in Nonlinear Science and Numerical Simulation, vol. 42, pp. 358-369, 2017.

[17] Tizhoosh HR., "Opposition-based learning: a new scheme for machine intelligence," Proceeding of the international conference on computational intelligence for modeling, control and automation, pp. 695-701, 2005.

[18] Ali Nasser Hussain, Ali Abdulabbas Abdullah, and Omar Muhammed Neda., "Modified Particle Swarm Optimization for Solution of Reactive Power Dispatch," Research Journal of Applied Sciences, Engineering and Technology, vol. 15(8), pp. 316-327, 2018.

[19] IEEE, The IEEE-test systems, 1993. [Online] Available: http://www.ee.washington.edu/trsearch/pstca/

[20] S. S. Reddy, et al., "Faster evolutionary algorithm based optimal power flow using incremental variables," Electrical Power and Energy Systems, vol. 54, pp. 198-210, 2014.

[21] S. Surender Reddy., "Optimal Reactive Power Scheduling Using Cuckoo Search Algorithm," International Journal of Electrical and Computer Engineering, vol. 7(5), pp. 2349-2356, 2017.

\section{APPENDIX}

Table 11. Simulation results of IEEE -118 system

\begin{tabular}{|c|c|c|c|c|c|c|}
\hline & Base case & MPSO [18] & PSO [18] & PSO [18] & CLPSO [18] & $\mathrm{OKS}$ \\
\hline$V G 1$ & 0.955 & 1.021 & 1.019 & 1.085 & 1.033 & 1.012 \\
\hline$V G 4$ & 0.998 & 1.044 & 1.038 & 1.042 & 1.055 & 1.016 \\
\hline$V G 6$ & 0.990 & 1.044 & 1.044 & 1.080 & 0.975 & 1.028 \\
\hline$V G 8$ & 1.015 & 1.063 & 1.039 & 0.968 & 0.966 & 1.019 \\
\hline$V G 10$ & 1.050 & 1.084 & 1.040 & 1.075 & 0.981 & 1.012 \\
\hline$V G 12$ & 0.990 & 1.032 & 1.029 & 1.022 & 1.009 & 1.028 \\
\hline$V G 15$ & 0.970 & 1.024 & 1.020 & 1.078 & 0.978 & 1.019 \\
\hline$V G 18$ & 0.973 & 1.042 & 1.016 & 1.049 & 1.079 & 1.006 \\
\hline$V G 19$ & 0.962 & 1.031 & 1.015 & 1.077 & 1.080 & 1.015 \\
\hline$V G 24$ & 0.992 & 1.058 & 1.033 & 1.082 & 1.028 & 1.014 \\
\hline$V G 25$ & 1.050 & 1.064 & 1.059 & 0.956 & 1.030 & 1.013 \\
\hline$V G 26$ & 1.015 & 1.033 & 1.049 & 1.080 & 0.987 & 1.022 \\
\hline$V G 27$ & 0.968 & 1.020 & 1.021 & 1.087 & 1.015 & 0.909 \\
\hline$V G 31$ & 0.967 & 1.023 & 1.012 & 0.960 & 0.961 & 0.906 \\
\hline$V G 32$ & 0.963 & 1.023 & 1.018 & 1.100 & 0.985 & 0.905 \\
\hline$V G 34$ & 0.984 & 1.034 & 1.023 & 0.961 & 1.015 & 1.014 \\
\hline$V G 36$ & 0.980 & 1.035 & 1.014 & 1.036 & 1.084 & 1.003 \\
\hline$V G 40$ & 0.970 & 1.016 & 1.015 & 1.091 & 0.983 & 0.950 \\
\hline$V G 42$ & 0.985 & 1.019 & 1.015 & 0.970 & 1.051 & 1.008 \\
\hline$V G 46$ & 1.005 & 1.010 & 1.017 & 1.039 & 0.975 & 1.010 \\
\hline$V G 49$ & 1.025 & 1.045 & 1.030 & 1.083 & 0.983 & 1.011 \\
\hline$V G 54$ & 0.955 & 1.029 & 1.020 & 0.976 & 0.963 & 0.912 \\
\hline$V G 55$ & 0.952 & 1.031 & 1.017 & 1.010 & 0.971 & 0.929 \\
\hline VG56 & 0.954 & 1.029 & 1.018 & 0.953 & 1.025 & 0.944 \\
\hline$V G 59$ & 0.985 & 1.052 & 1.042 & 0.967 & 1.000 & 0.932 \\
\hline$V G 61$ & 0.995 & 1.042 & 1.029 & 1.093 & 1.077 & 0.910 \\
\hline$V G 62$ & 0.998 & 1.029 & 1.029 & 1.097 & 1.048 & 0.922 \\
\hline$V G 65$ & 1.005 & 1.054 & 1.042 & 1.089 & 0.968 & 1.006 \\
\hline$V G 66$ & 1.050 & 1.056 & 1.054 & 1.086 & 0.964 & 1.049 \\
\hline$V G 69$ & 1.035 & 1.072 & 1.058 & 0.966 & 0.957 & 1.012 \\
\hline$V G 70$ & 0.984 & 1.040 & 1.031 & 1.078 & 0.976 & 1.010 \\
\hline$V G 72$ & 0.980 & 1.039 & 1.039 & 0.950 & 1.024 & 1.008 \\
\hline$V G 73$ & 0.991 & 1.028 & 1.015 & 0.972 & 0.965 & 1.009 \\
\hline$V G 74$ & 0.958 & 1.032 & 1.029 & 0.971 & 1.073 & 1.002 \\
\hline$V G 76$ & 0.943 & 1.005 & 1.021 & 0.960 & 1.030 & 1.006 \\
\hline$V G 77$ & 1.006 & 1.038 & 1.026 & 1.078 & 1.027 & 1.008 \\
\hline$V G 80$ & 1.040 & 1.049 & 1.038 & 1.078 & 0.985 & 1.004 \\
\hline$V G 85$ & 0.985 & 1.024 & 1.024 & 0.956 & 0.983 & 1.010 \\
\hline$V G 87$ & 1.015 & 1.019 & 1.022 & 0.964 & 1.088 & 1.002 \\
\hline$V G 89$ & 1.000 & 1.074 & 1.061 & 0.974 & 0.989 & 1.031 \\
\hline$V G 90$ & 1.005 & 1.045 & 1.032 & 1.024 & 0.990 & 1.010 \\
\hline$V G 91$ & 0.980 & 1.052 & 1.033 & 0.961 & 1.028 & 1.009 \\
\hline$V G 92$ & 0.990 & 1.058 & 1.038 & 0.956 & 0.976 & 1.018 \\
\hline$V G 99$ & 1.010 & 1.023 & 1.037 & 0.954 & 1.088 & 1.005 \\
\hline$V G 100$ & 1.017 & 1.049 & 1.037 & 0.958 & 0.961 & 1.003 \\
\hline$V G 103$ & 1.010 & 1.045 & 1.031 & 1.016 & 0.961 & 1.009 \\
\hline$V G 104$ & 0.971 & 1.035 & 1.031 & 1.099 & 1.012 & 1.017 \\
\hline$V G 105$ & 0.965 & 1.043 & 1.029 & 0.969 & 1.068 & 1.028 \\
\hline
\end{tabular}

Active power loss reduction by opposition based kidney search algorithm (K. Lenin) 
Table 11. Simulation results of IEEE -118 system (continued)

\begin{tabular}{|c|c|c|c|c|c|c|}
\hline & Base case & MPSO [18] & PSO [18] & PSO [18] & CLPSO [18] & $\mathrm{OKS}$ \\
\hline$V G 107$ & 0.952 & 1.023 & 1.008 & 0.965 & 0.976 & 1.012 \\
\hline$V G 110$ & 0.973 & 1.032 & 1.028 & 1.087 & 1.041 & 1.016 \\
\hline$V G 111$ & 0.980 & 1.035 & 1.039 & 1.037 & 0.979 & 1.019 \\
\hline$V G 112$ & 0.975 & 1.018 & 1.019 & 1.092 & 0.976 & 1.092 \\
\hline$V G 113$ & 0.993 & 1.043 & 1.027 & 1.075 & 0.972 & 1.016 \\
\hline$V G 116$ & 1.005 & 1.011 & 1.031 & 0.959 & 1.033 & 1.018 \\
\hline Tap 8 & 0.985 & 0.999 & 0.994 & 1.011 & 1.004 & 0.932 \\
\hline Tap 32 & 0.960 & 1.017 & 1.013 & 1.090 & 1.060 & 1.004 \\
\hline Tap 36 & 0.960 & 0.994 & 0.997 & 1.003 & 1.000 & 0.949 \\
\hline Tap 51 & 0.935 & 0.998 & 1.000 & 1.000 & 1.000 & 0.912 \\
\hline Tap 93 & 0.960 & 1.000 & 0.997 & 1.008 & 0.992 & 1.018 \\
\hline Tap 95 & 0.985 & 0.995 & 1.020 & 1.032 & 1.007 & 0.930 \\
\hline Tap 102 & 0.935 & 1.024 & 1.004 & 0.944 & 1.061 & 1.012 \\
\hline Tap 107 & 0.935 & 0.989 & 1.008 & 0.906 & 0.930 & 0.930 \\
\hline Tap 127 & 0.935 & 1.010 & 1.009 & 0.967 & 0.957 & 1.014 \\
\hline QC 34 & 0.140 & 0.049 & 0.048 & 0.093 & 0.117 & 0.010 \\
\hline$Q C 44$ & 0.100 & 0.026 & 0.026 & 0.093 & 0.098 & 0.024 \\
\hline$Q C 45$ & 0.100 & 0.196 & 0.197 & 0.086 & 0.094 & 0.110 \\
\hline$Q C 46$ & 0.100 & 0.117 & 0.118 & 0.089 & 0.026 & 0.109 \\
\hline$Q C 48$ & 0.150 & 0.056 & 0.056 & 0.118 & 0.028 & 0.020 \\
\hline$Q C 74$ & 0.120 & 0.120 & 0.120 & 0.046 & 0.005 & 0.112 \\
\hline$Q C 79$ & 0.200 & 0.139 & 0.140 & 0.105 & 0.148 & 0.109 \\
\hline$Q C 82$ & 0.200 & 0.180 & 0.180 & 0.164 & 0.194 & 0.140 \\
\hline$Q C 83$ & 0.100 & 0.166 & 0.166 & 0.096 & 0.069 & 0.106 \\
\hline$Q C 105$ & 0.200 & 0.189 & 0.190 & 0.089 & 0.090 & 0.110 \\
\hline QC 107 & 0.060 & 0.128 & 0.129 & 0.050 & 0.049 & 0.121 \\
\hline$Q C 110$ & 0.060 & 0.014 & 0.014 & 0.055 & 0.022 & 0.015 \\
\hline PG(MW) & 4374.8 & 4359.3 & 4361.4 & $\mathrm{NR}^{*}$ & $\mathrm{NR}^{*}$ & 4358.02 \\
\hline QG(MVAR) & 795.6 & 604.3 & 653.5 & $* \mathrm{NR} *$ & $\mathrm{NR}^{*}$ & 605.97 \\
\hline Reduction in PLOSS (\%) & 0 & 11.7 & 10.1 & 0.6 & 1.3 & 13.38 \\
\hline Total PLOSS (Mw) & 132.8 & 117.19 & 119.34 & 131.99 & 130.96 & 115.02 \\
\hline
\end{tabular}

NR* - Not reported. 